\title{
APORÍAS NARRATIVAS EN LUCÍA Y EL SEXO DE JULIO MEDEM
}

\section{APORIES NARRATIVES DANS LUCÍA Y EL SEXO DE JULIO MEDEM}

\author{
Pascale Thibaudeau \\ Universidad París 8
}

\section{Resumen:}

Este artículo propone un estudio de la estructura narrativa de la película Lucía y el sexo de Julio Medem a partir de algunas nociones deconstructivistas sintetizadas en la introducción. Los juegos elaborados por la instancia enunciadora alrededor de los distintos niveles internos de narración provocan regularmente un cuestionamiento de los límites entre ficción y realidad que parecían haber sido definidos anteriormente y desembocan en una forma de "indecidabilidad" narrativa.

El proceso de escritura puesto en escena por la película (el protagonista es escritor) justifica las innumerables vías que toma una narración que se va construyendo bajo nuestra mirada y donde todo participa en la descomposición de la linearidad del relato. Constantemente desplazado, el lugar de donde procede la narración se virtualiza, lo que favorece la multiplicación de pistas de interpretación contradictorias entre las que ninguna se revela, de por sí, satisfactoria. En permanente proceso de diseminación y de "diferancia" del sentido, esta película entra en resonancia con las aporías deconstructivistas.nacional-católicos.

\begin{abstract}
:
Cet article se propose d'étudier la structure narrative du film Lucía y el sexo de Julio Medem à partir de quelques notions déconstructivistes rappelées en introduction. Les jeux mis en place par l'instance énonciatrice autour des différents niveaux de narration internes provoquent régulièrement une remise en cause des limites entre fiction et réalité qui semblaient avoir été définies auparavant, et aboutissent à une forme d"'indécidabilité narrative".

Le processus d'écriture mis en scène par le film (le personnage principal est écrivain) justifie les nombreuses voies qu'emprunte une narration qui se construit sous nos yeux et où tout concourt à décomposer la linéarité du récit. Sans cesse déplacé, le lieu d'où émane la narration se virtualise, ce qui contribue à multiplier des pistes interprétatives contradictoires dont aucune ne s'avère, isolément, satisfaisante. En constant processus de dissémination et de « différance » du sens, le film entre ainsi en résonance avec les apories déconstructivistes.
\end{abstract}

\section{Palabras clave:}

Deconstrucción; narración; escritura; Julio Medem; montaje

Key words:

Déconstruction; narration; écriture; Julio Medem; montage 
Este trabajo se apoya sobre la noción de deconstrucción elaborada por Jacques Derrida a lo largo de sus comentarios de textos filosóficos, críticos y literarios, y no entendida como proceso de destrucción o descomposición al que a veces se asimila por mera proximidad semántico-lexical. ${ }^{1}$ El propio Derrida aclara al respecto: «Desde el principio se ha dicho claramente que la deconstrucción no es un proceso o un proyecto marcado por la negatividad, ni siquiera en lo esencial por la "crítica" [...]. La deconstrucción es, antes que nada, la reafirmación de un "sí" originario. Afirmativo no significa positivo. Preciso esquemáticamente este punto para explicar que, al reducirse para algunos la afirmación a la posición de lo positivo, la deconstrucción esté destinada a re-construir después de una fase de demolición. No, no hay más demolición que reconstrucción positiva, y no hay fases» ${ }^{2}$. El propio término «deconstrucción» proviene de la traducción que propone Derrida para el proyecto heideggeriano de destrucción de la historia de la ontología con el objetivo de subrayar que no se trata precisamente de destrucción sino de descomposición analítica y de puesta al día (ZYMA, 1994: 34).

Recordemos rápidamente que la deconstrucción consiste en un cuestionamiento de una tradición filosófica institucionalizada poniendo de manifiesto sus ambigüedades y contradicciones internas. Derrida se lanzó a una lectura deconstructivista, pero en absoluto destructora, del discurso de Kant sobre el arte, del logocentrismo de Hegel o del sistema lingüístico de Saussure, entre otras cosas. En los dos últimos casos sacó a la luz las presuposiciones metafísicas y algunos de los conceptos idealistas que los sostenían de forma paradójica. Puso así de manifiesto hasta qué punto el lenguaje racional filosófico y crítico se fundamenta sobre bases aporéticas.

\footnotetext{
${ }^{1}$ Este artículo es la traducción de un texto ya publicado en Francia: «Déconstruction narrative dans Lucía y el sexo» en Marie-Soledad Rodríguez (ed.), Le cinéma de Julio Medem, Paris, Presses de la Sorbonne Nouvelle, 2008, pp. 81-97

2. «Dès le début, il a été clairement dit que la déconstruction n'est pas un processus ou un projet marqué par la négativité, pas même, pour l'essentiel par la "critique" [...]. La déconstruction est avant tout la réaffirmation d'un "oui" originaire. Affirmatif ne veut pas dire positif. Je précise schématiquement ce point pour expliquer que, pour certains l'affirmation se réduisant à la position du positif, la déconstruction soit vouée à re-construire après une phase de démolition. Non, il n'y a pas plus démolition que reconstruction positive, et il n'y a pas de phase», (DERRIDA, 2002: 50). Todas las traducciones al castellano de las obras en francés citadas son de la autora del artículo.
} 
En efecto, lo que distingue radicalmente el movimiento deconstructivista de los sistemas racionalistas filosóficos es que no rechaza el caos sino que lo acepta - lo cual no significa que lo reivindique - como parte constitutiva del pensamiento. Por esta razón la deconstrucción aplicada a los textos 3 tiende a poner de relieve la existencia de múltiples significaciones, incluso incompatibles en términos lógicos, en vez de proclamar una verdad única e insuperable4. Ello implica que el sentido no esté presente sino constantemente ya diferido en un proceso de «diferancia» 5 relacionado por una parte con la heterogeneidad de los contextos de comunicación, y por otra con los cambios y deslizamientos semánticos internos al propio discurso. Desde esta perspectiva, un factor importante de cambio interno es la repetición o recurrencia de un signo que desemboca en la dispersión del sentido; fenómeno que Derrida nombra «iterabilidad» en oposición a la «iteratividad» que los estructuralistas (Greimas, Courtés) conciben como factor de consolidación y homogeneidad de lo enunciado.

En su manera de enfocar los textos, la deconstrucción invita a reflexionar sobre las paradojas inherentes a la razón, a reconocer el carácter contradictorio e indecidible de los textos en vez de someterlos a un discurso conceptual y teórico previo. Considerado esto, se entiende que todo texto se deconstruye a sí mismo (inclusive los de Derrida) y que se construye deconstruyéndose. Si no, no se podría hablar de él ni criticarlo ni intentar explicarlo.

Esta introducción a pesar de su carácter esquemático me permite indicar algunos de los jalones que van a guiar mi reflexión y aclarar la acepción que se le da aquí a «deconstrucción», para evitar que se tome en el sentido literal de la palabra y que se reduzca lo que es un pensamiento complejo a un

3. Derrida rechaza las fronteras genéricas habituales entre literatura, crítica y filosofía.

4. Sobre la relación entre el pensamiento derridiano y la verdad, ver (GROSSMAN, 2004: 1822; GARCÍA DÜTTMANN, 2004).

5. Jacques Derrida establece una distinción entre «diferencia» (différence) y «diferancia» (différance) que incluye la idea de lo diferido; esta precisión aparece en (DERRIDA, 1972). 
proceso de derrumbamiento de la filosofía o de desmoronamiento de los «valores» 6 .

Sentadas las bases teóricas de esta contribución, voy a centrarme ahora sobre la organización de la narración en Lucía y el sexo, cuestión central puesto que uno de los protagonistas de la película, Lorenzo, es escritor y aparece a menudo escribiendo en su ordenador páginas de novelas íntimamente relacionadas con su vida. $\mathrm{Al}$ poner en imágenes fragmentos de las ficciones secundarias escritas por Lorenzo, la enunciación primera -el nivel de enunciación impersonal definido por Christian Metz (METZ, 1991) - va a mezclar los distintos niveles ficcionales hasta que las fronteras que los delimitan queden completamente abolidas. La perturbación perceptiva que tal procedimiento implica así como la imposibilidad para el espectador de asignarles zonas claramente determinadas a las ficciones novelescas y a la ficción fílmica que las engloba son elementos que nos permiten comprobar hasta qué punto las nociones deconstructivistas de diseminación, de «diferancia» del sentido, de «indecidibilidad» de la interpretación, de «inevitabilidad» de la aporía, son nociones que han penetrado en áreas intermediarias de expresión artística a las que pertenece el cine de Medem. Por «área intermediaria» designo una forma de expresión porosa, permeable a la evolución del pensamiento, de la que emergen pretensiones autoriales pero sin dejar de pertenecer a circuitos comerciales que implican la observancia de cierto número de códigos.

La deconstrucción filosófico-literaria «diseminó» en el pensamiento y las artes de la segunda mitad del siglo XX y principios del siglo XXI, gérmenes que han brotado en obras características de la posmodernidad, en un proceso de hibridación inherente a todo pensamiento que se expande7. Esta

\footnotetext{
6. Las mayores críticas a la deconstrucción derridiana fueron formuladas a partir del movimiento de la escuela de Francfort por discípulos de Adorno y Orkheimer, así como por Habermas y Bourdieu en torno a la exclusión de los determinantes socio-históricos y a la asimilación de las ciencias sociales a discursos metafísicos. Estas críticas se remontan a los años 80 y no toman en cuenta el giro ético-político que Derrida le dio a su reflexión en los años 90 (Spectres de Marx, Politiques de l'amitié...).

7. De hecho, partiendo de la crítica que hace Jürgen Habermas de la deconstrucción en (1988): Le discours philosophique de la modernité, Paris, Gallimard, se puede concebir la posmodernidad como un avatar popular de la deconstrucción.
} 
deconstrucción desvirtuada, popularizada, en la que se han esfumado los postulados filosóficos iniciales, de la que sólo quedan huellas (motivo muy derridiano), estos restos habitan y determinan una buena parte del arte visual, audiovisual y literario contemporáneo, propenso a la «indecidibilidad» cuando no a las aporías.

En lo que refiere al cine de ficción de Medem, nos encontramos frente a películas globalmente narrativas, películas que proponen una estructura narrativa e intrigas más o menos reconstituibles según principios de lógica y de cronología. Sin embargo, son películas que al mismo tiempo no se pueden reducir a su cuerpo narrativo, juegan con efectos de ruptura, están saturadas de signos insistentes y van cuestionando, a lo largo de su desarrollo, la transparencia narrativa hasta que ésta acabe oscureciéndose. Así que se puede decir que, en cierto modo, el cine de ficción de Medem exhibe la opacidad narrativa, nos cuenta historias que, parafraseando a Jean-Luc Godard, tienen «un principio, un centro y un final pero no forzosamente en este orden». Es más, estas películas no se limitan a alterar el orden narrativo común sino que postulan a la vez la transparencia narrativa y su imposibilidad, la linealidad y su fracaso, por lo cual son textos «ilegibles» en el sentido deconstructor de la palabra. Hasta parece que se toman al pie de la letra, para ilustrarlo y vulgarizarlo, el trabajo de deconstrucción al que Derrida sometió el discurso filosófico y la crítica literaria. Las aporías que acabo de mencionar se pueden detectar ya en films como La ardilla roja o Los amantes del círculo polar pero se manifiestan con más nitidez en Lucía y el sexo que vamos a analizar ahora más detalladamente.

$\mathrm{Al}$ cabo de doce minutos de narración lineal, empieza un largo flash-back que inaugura una alternancia entre un pasado y un presente asociados a lugares. Al pasado, que ocurrió seis años antes, le corresponde Madrid como espacio y al presente una isla que los títulos de crédito nos permiten identificar como la de Formentera pero que no está nombrada en ningún momento de la película y que tiene características extrañas como la de no estar relacionada con la tierra. Uno de los personajes Carlos (en otras ocasiones llamado Antonio) dice: «Esto en realidad no es una isla [...] es una tapadera, un trozo 
de tierra que flota, como una balsa [...] los días de mar gruesa, la gente se marea y nadie sabe por qué [...]. Yo he buceado por debajo de toda la isla, está totalmente hueca, hay miles de cuevas, pero nada. No he visto ni un sólo trozo de roca que la una al fondo del mar». Ya, desde este principio de alternancia espacio-temporal bastante clásica, se introducen gérmenes de duda sobre la adecuación entre la realidad y su apariencia, pero, además, a esta primera alternancia se va a añadir otra - dentro del mismo flash-backque es la alternancia entre la realidad diegética (a la cual pertenecen el pasado y el presente) y las ficciones escritas por Lorenzo.

Son tres relatos sucesivos que corresponden a etapas distintas en la vida del escritor y se nutren aparentemente de su experiencia vital. El primer relato subraya el proceso de transformación de la «realidad» vivida por Lorenzo en material novelesco. Esta ficción tiene como protagonista una mujer que retoma características de Elena (una amante de paso) y de Lucía con la que comparte su vida: «El restaurante se hizo famoso en Madrid gracias a las paellas de aquella joven solitaria y sin habla que aún seguía recordando a su abuela enterrada en el pueblo junto a sus padres. Cuando algún cliente se interesaba por ella, para justificar su timidez respondía que era de Malta». Esta historia se la sugiere su amigo Pepe ante la falta de inspiración de Lorenzo: «¿Por qué no recuperas aquella historia que me contaste, la de la isla?», Lorenzo: «¿Con la valenciana? Puede ser...» [...], Pepe: «Pues mete mucho sexo, que siempre se agradece». Esta última observación de Pepe suena como un comentario de lo que vemos, después, de la relación entre Lorenzo y Lucía, relación que pertenece supuestamente a la realidad diegética, por lo cual, la frase de Pepe anuncia la permeabilidad futura entre los distintos niveles de diégesis.

La segunda ficción que Lorenzo se lanza a escribir hace menos firmes todavía los límites entre lo que escribe y lo que vive, pero sobre todo entre lo que pertenece a la enunciación primera de la película y lo que proviene del relato de Lorenzo. Por segunda vez el personaje que desencadena el proceso de escritura es Pepe cuando le revela a Lorenzo, el día de su cumpleaños, la existencia de una hija suya nacida de su breve encuentro con Elena y llamada 
Luna. Acaba concluyendo: «Si esto lo escribes bien, puede ser el relato de tu vida y... mi regalo de cumpleaños». Evidentemente, la locución «el relato de tu vida» es ambivalente, se puede entender como «el mejor relato que hayas escrito en tu vida» o como una propuesta de escribir su autobiografía. En esta ambigüedad se fundan todas las transgresiones metalépticas que siguen. Gérard Genette apuntó como «metalepsis narrativa», todos los juegos que «manifiestan por la intensidad de sus efectos la importancia del límite que se ingenian en franquear con desprecio de la verosimilitud, y que es precisamente la misma narración (o representación), frontera movediza pero sagrada entre dos mundos: el mundo desde el que se narra y el mundo que se narra» ${ }^{8}$. Cuando, después de haber leído lo que escribió Lorenzo del encuentro con Luna, Lucía le pregunta si tiene una hija, él le contesta que no tiene la menor idea de lo que es ser padre y ella, entusiasmada por lo que ha leído, exclama: «Pues invéntatelo». En ese momento de la película la frontera entre los dos mundos, además de desplazarse constantemente, se va borrando. Las semillas diseminadas desde el principio han germinado hasta crear un entramado de brotes difícilmente disociables y jerarquizables.

En efecto, a partir del encuentro con Luna - del que el espectador nunca podrá decir si ha tenido lugar en la realidad diegética o solamente en la ficción metadiegética-, los distintos niveles van a mezclarse todavía más. La confusión creciente se produce mediante la transformación en imágenes del relato de Lorenzo simultáneamente a su escritura y porque esta narración en imágenes con voz en off va a desdoblarse a su vez en proceso de lectura visualizada por Lucía. Al mismo tiempo que se superponen los niveles narrativos, también se superponen las instancias de emisión y de recepción del texto que es a la vez fílmico y literario. El lugar de la enunciación se vuelve múltiple e indiscernible.

Después de encontrarse en una plaza con Luna y Belén, su joven niñera, Lorenzo escribe en su ordenador un diálogo entre la niña y su padre. A los

8. « Tous ces jeux manifestent par l'intensité de leurs effets l'importance de la limite qu'ils s'ingénient à franchir au mépris de la vraisemblance, et qui est précisément la narration (ou la représentation) elle-même; frontière mouvante mais sacrée entre deux mondes: celui où l'on raconte, celui que l'on raconte» (GENETTE, 1972: 245). 
planos del escritor trabajando en el ático suceden planos de Luna y Lorenzo en una playa prosiguiendo el diálogo novelesco referido antes por la voz en off. El espectador identifica estos planos como la visualización de la narración a cargo de Lorenzo. Sin embargo, cuando volvemos al apartamento, él ha desaparecido y ha sido sustituido por Lucía, a la que vemos leyendo en la pantalla del ordenador lo que anteriormente escribió su amante 9 .

El plano de Lorenzo saliendo de la plaza en la que vio por primera vez a su hija es un plano de marcada estética manierista. La saturación de luz y color exhibe la utilización de filtros lo cual contrasta con el ambiente relativamente realista de la secuencia anterior como si ya no le perteneciera. Y, de hecho, ya en este plano se empieza a oír el ruido del teclado del ordenador de Lorenzo y su voz en off transmitiéndonos lo que está escribiendo. El lugar que las imágenes le asignan luego a la ficción es una playa que no deja de remitir a la isla asociada de repente con un espacio ficcional. La saturación luminosa, los fuertes contrapicados y la utilización de un objetivo de gran angular contribuyen a conferirle a este espacio una atmósfera irreal. Lo interesante en la secuencia es observar cómo se opera un deslizamiento entre lo que el espectador identifica como lo real (el encuentro en la plaza, Lorenzo escribiendo en el ordenador y Lucía leyendo en la pantalla) y la escena ficcional de la isla. Algunos procedimientos del montaje crean una contiguildad entre los dos niveles mientras que otros, como los fundidos encadenados, marcan el cambio de nivel. Los procedimientos de contiguïdad

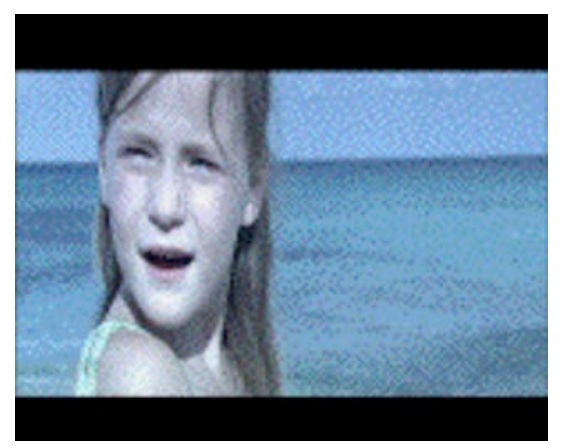

Figura 1 ¿Mi padre de verdad?

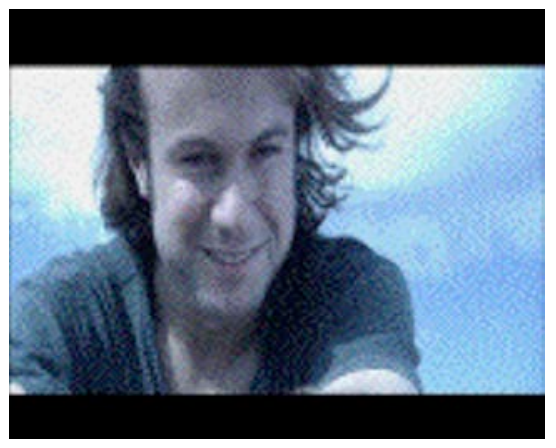

Figura 2 son, por ejemplo, la respuesta de Luna en el nivel metadiegético a una pregunta

\footnotetext{
9. Esta secuencia corresponde al capítulo 9 de la edición DVD de la película, Sogepaq/ Universal Pictures Spain, 2001.
} 
hecha por Lorenzo en el nivel diegético (Lorenzo pregunta en el ático: «¿Sabes cómo se llama?», Luna contesta en la playa: «No».), o el contracampo entre un plano cercano de Lorenzo en la playa sonriendo ante una pregunta de Luna (figuras 1 y 2) y otro plano cercano de Lucía sonriendo

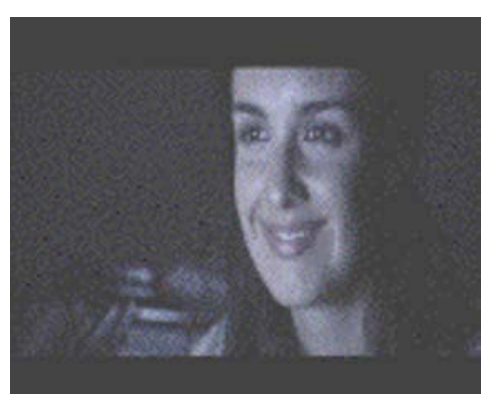
ante la pantalla del ordenador (figura 3) después de leer la misma pregunta, como si las dos sonrisas se respondieran. Al principio de la secuencia, el montaje alternado establece de manera clásica una relación de simultaneidad entre los planos de Lorenzo escribiendo y los planos en la playa -éstos apareciendo como imágenes mentales del escritor-, luego, el mismo tipo de montaje es utilizado para significar la sustitución de Lorenzo por Lucía delante de la pantalla del ordenador sin que ningún rasgo retórico lo anuncie. De repente, en un pliegue del montaje, se ha colado una elipsis temporal, en medio de la simultaneidad. El contracampo establece un paralelismo entre Lorenzo-escritor y Lucía-lectora, y tanto ella como él son el foco del que emanan las imágenes aunque el proceso de lectura sea posterior. La visualización de la narración secundaria sitúa en un mismo plano al emisor y al receptor explorando así la función creadora de este último. Por la interfaz de la pantalla del ordenador se abren las compuertas que hacen comunicar los distintos niveles narrativos y permiten su mutua contaminación ${ }^{10}$.

La tercera ficción es la más compleja dado que incluye elementos de la segunda y va a desbordarse, mediante el personaje de Antonio/Carlos, sobre la realidad diegética de la isla. Este relato nace del encuentro con Belén, la niñera de Luna, cuando ésta le revela que su madre fue actriz pornográfica.

\footnotetext{
10. Una contaminación fascinante, según Borges: «Semejantes invenciones sugieren que si los personajes de una ficción pueden ser lectores o espectadores, sus lectores o espectadores podemos ser personajes ficticios», citado por Gérard Genette, quien comenta: «Lo más pertubador de la metalepsis se encuentra en esta hipótesis inaceptable e insistente, de que lo extradiegético es, quizás, siempre ya diegético, y que el narrador y sus narratarios, es decir usted y yo, pertenecemos quizás a algún relato más» («Le plus troublant de la métalepse est bien dans cette hypothèse inacceptable et insistante, que l'extradiégétique est peut-être toujours déjà diégétique, et que le narrateur et ses narrataires, c'est-àdire vous et moi, appartenons peut-être encore à quelque récit») (GENETTE, 1972: 245).
}

27 
Las frases con las que Lorenzo puntúa el diálogo parecen ser comentarios sobre el relato mismo más que sobre lo que le cuenta Belén («Me gusta», «Eso suena bien») como si ya, al oirlo, fuera material novelesco. En seguida empieza, entre la escena en la plaza y el apartamento donde escribe Lorenzo, un vaivén parecido al que vimos entre la escena de la playa y Lorenzo. El paralelismo del tratamiento fílmico obliga al espectador a dudar de la realidad del encuentro con Belén: se ve a Lorenzo escribiendo en el ordenador y haciendo en voz alta la pregunta «¿A ti también te gusta?» (figura 4). En el plano siguiente, se ve a Belén con Lorenzo en la plaza replicando: «¿A mí? ¿Por qué, se me nota?» (figura 5). Otra secuencia ${ }^{11}$, más tarde, presenta a Lorenzo escribiendo y relatando cómo Antonio, el padrastro de Belén la sorprendió en la ducha. En las imágenes que acompañan al relato

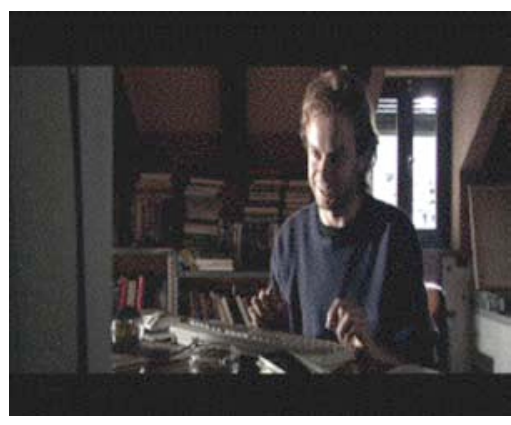

Figura 4. Lorenzo: ¿A ti también te gusta?

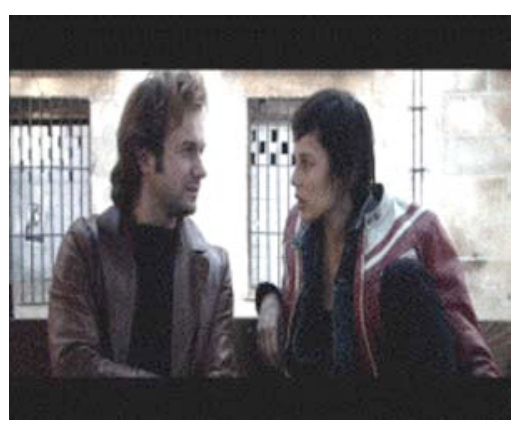

Figura 5. ¿A mí? ¿Por qué, se me nota?

vemos primero que el propio Lorenzo sustituye a Antonio y luego que Belén se ha metamorfoseado en Lucía. La realidad del personaje de Belén es así sometida a cuestionamiento, aparece más como un avatar fantasmático de Lucía, una proyección literaria, que como un personaje real, pero esta hipótesis tampoco se puede garantizar. No es que Belén sea a la vez personaje real y personaje de ficción sino que es a la vez personaje real y de ficción más sólo personaje de ficción.

A partir de ahí los límites que el espectador se esforzaba en trazar entre los distintos niveles narrativos pierden todavía más consistencia y el nivel de la enunciación primera va a contaminarse cada vez más. De todos los hechos referidos, entre los cuales la muerte de Luna, ¿pertenecen algunos a la realidad o todos forman parte de una ficción más global narrada por el 11. Capítulo 11 de la edición DVD. 
propio Lorenzo? Desde el principio de la película un elemento permite inferir esta fusión de niveles: los títulos de crédito aparecen sobre planos de fondos marinos como si fuesen tecleados en la pantalla de un ordenador mientras se va oyendo cada vez más nítidamente el ruido de las teclas. Este indicio inicial, aislado al principio, cobra sentido cuando ya se ha vuelto inextricable la red de correspondencias entre la supuesta realidad diegética y los distintos niveles metadiegéticos. Luego, a lo largo de su desarrollo, la película va cuestionando las mismas categorías de diégesis y metadiégesis. Al hacerlas fusionar, la propia enunciación va invalidando progresivamente los límites que había marcado anteriormente. $\mathrm{Y}$, de hecho, si lo pensamos en términos deconstructivistas, la noción de metalepsis acarrea la abolición de los límites al mismo tiempo que los define, se sostiene en las categorías que deshace.

Los tres relatos sucesivos escritos por Lorenzo instauran una aparente alternancia entre la realidad y la ficción en la que, al principio, la ficción se nutre de la realidad pero donde, rápidamente, se produce lo contrario, siendo la ficción la que empieza a influir en la realidad. Hemos visto con algunos ejemplos que existe una gradación hacia una mayor complejidad a lo largo del desarrollo fílmico. Se añade a ello un metadiscurso sobre la elaboración del relato a cargo del personaje de Lorenzo y este metadiscurso va a ser corroborado, de cierta manera, por los acontecimientos narrados y la estructura repetitiva que va adquiriendo la película.

La negación de la linealidad es proferida por el mismo Lorenzo cuando apuesta por un relato que no tenga final. Ya han pasado 80 minutos de la película cuando Lorenzo, chateando con Elena -cuyo nombre de chat es Alsi, anagrama de «isla»-, le escribe: «Quiero escribirte un cuento lleno de ventajas. [...] La primera ventaja es que cuando el cuento llega al final, no se acaba, sino que se cae por un agujero [imita el ruido de la caída], y el cuento reaparece en mitad del cuento. Ésta es la segunda ventaja y la más grande, que desde aquí se le puede cambiar el rumbo si tú me dejas, si me das tiempo». Esta propuesta que suena a teoría literaria cortazariana es un eco del cuento que Lorenzo le contó a Luna poco antes de su muerte: «[...] también es la isla del buen tiempo, y la isla de los deseos. Si te falta algo, las 
rocas del fondo del mar te lo hacen y cuando lo tengan acabado te lo regalan. Sólo hay que tener cuidado con una cosa, los agujeros del suelo. Aunque no importa mucho porque también es la isla en la que nadie se muere. Por ejemplo... si te caes, luego puedes elegir la vida que quieras. O ser el pez que más te guste». Un pez que podría muy bien morderse la cola, narrativamente hablando. La ficción, explicada a un público infantil, aparece pues como una isla, este espacio cortado del resto del mundo en el que van a refugiarse varios personajes ${ }^{12}$, este lugar en el que se pueden rectificar las malas orientaciones que coge a veces la realidad, este lugar único en el mundo donde se puede escapar de la muerte. En la versión para adultos, el cuento lleno de ventajas que le propone Lorenzo a Elena es, por supuesto, una definición autorreflexiva del relato de la película que no deja de volver sobre sí mismo para explorar nuevas pistas y evitar, precisamente, que mueran los personajes.

Así, los últimos planos de la película parecen devolverle la vida a Luna arrancándola a la fijeza de la fotografía, esto es a la inmovilidad de la muerte. En la pensión de la isla vemos a Elena con la cara bañada en lágrimas acercándose a la foto de su hija colgada de la pared mientras se oye la voz en off de Lorenzo repitiendo palabra por palabra las características del relato que nunca se acaba citado más arriba. Un plano subjetivo en travelín de avance se aproxima a la foto (figura 6) y, mientras se oye en off a Lorenzo imitando el ruido de la caída en el agujero, un fundido encadenado (figura 7)

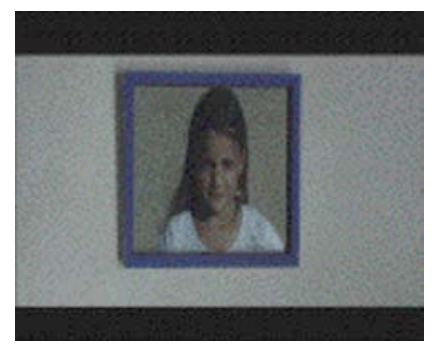

Figura 6

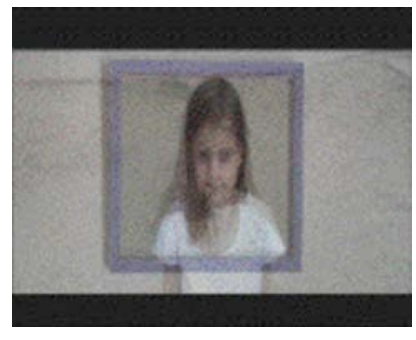

Figura 7

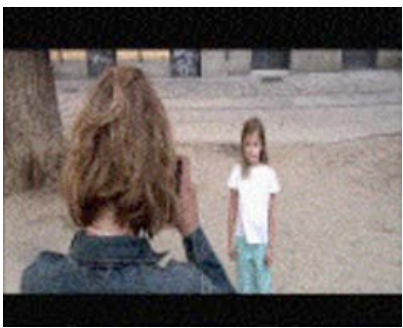

Figura 8

\footnotetext{
12. Lucía se refugia en la isla después del accidente de Lorenzo, Elena acude a ella tras la muerte de Luna y Antonio/Carlos se encuentra allí también después de la desaparición de Manuela y Belén. La isla puede verse como un espacio interior a la vez que exterior en el que los personajes heridos por la pérdida de seres queridos se refugian y huyen de cierto contacto con la realidad.
}

30 
nos hace retroceder en el tiempo y volver al momento en que fue sacada la foto (figura 8). Se escucha en este preciso instante: «y el cuento reaparece en mitad del cuento», y en seguida se oye el disparador de la máquina fotográfica; simultáneamente un travelín de retroceso hace entrar Elena de espaldas en el campo enfocando a Luna con la cámara de fotos. Las dos cruzan luego la plaza y salen del campo mientras un travelín vertical nos hace trepar por la fachada de un edificio hasta que entramos por una ventana en un apartamento donde descubrimos a Lorenzo escribiendo en su ordenador ${ }^{13}$ (figura 9). La situación y el movimiento de cámara crean un eco con unos planos de la primera parte de la película cuando Lorenzo empieza a escribir su primer relato después de su encuentro con Lucía (figura 10). Vemos a Elena en la misma plaza empujando un cochecito en el que está sentada Luna con unos meses. Un travelín similar sobre la fachada nos hace llegar al ático de Lorenzo donde está escribiendo en el ordenador.

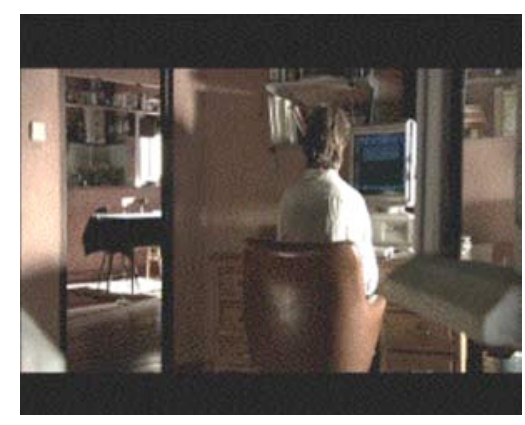

Figura 9

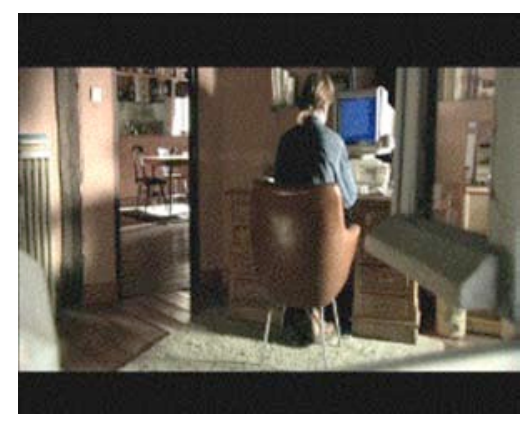

Figura 10

En el epílogo, el movimiento simétrico de los travelines (de avance y de retroceso), la voz en off de Lorenzo así como la iterabilidad de la secuencia que crea una rima interna en el film contribuyen a que la metamorfosis de la imagen fija en imagen en movimiento mediante el fundido encadenado no sea únicamente un salto temporal hacia el pasado. Al volver al momento en que fue sacada la foto se sugiere que el camino que cogió el relato para llegar a la muerte de Luna puede cambiarse por otro, como si esta posibilidad narrativa fuera tachada y sustituida por otra. De hecho, el travelín que llega al ático de Lorenzo, donde está escribiendo, señala una simultaneidad entre

13. La voz en off de Lorenzo puede interpretarse como una reminiscencia interior procedente de los pensamientos de Elena en la isla o/y como lo que está escribiendo Lorenzo en el momento en que Elena saca la foto en la plaza. 
el momento en que Elena y Luna cruzan la plaza y el momento en que él escribe su definición del cuento, puesto que la voz en off la repite en ese momento. Ahora bien, se supone, en una perspectiva de reconstrucción cronológica -que en sí es poco pertinente-, que esto se lo escribió a Elena/Alsi, después de la muerte de Luna, por lo que podemos considerar que, en esta última secuencia, Luna está a la vez viva y muerta. Lo que, en otra ocasión y a propósito de Los amantes del círculo polar, relacioné con la paradoja del gato de Schrödinger (THIBAUDEAU, 2005: 25-41) encuentra también cabida en las aporías deconstructivistas. Los últimos planos de Lucía y el sexo no resuelven nada: ¿estamos dentro del relato de Lorenzo o fuera? ¿Está contenida la película entera en el interior de un relato que se pone a sí mismo en abismo? No llega ninguna revelación al final, sólo se afirma la posibilidad de una reescritura constante.

El proceso de escritura puesto en escena en la película y definido por el propio Lorenzo justifica los múltiples rumbos que coge una narración que se va construyendo ante nuestros ojos: sustitución de unos personajes por otros, impasses narrativos, arrepentimientos, correcciones, repeticiones, modificaciones van descomponiendo la linealidad del relato. Los distintos estratos del proceso escriptural aparecen sucesivamente como variables posibles sin que se nos precise que es lo que fue definitivamente tachado por la instancia enunciadora ${ }^{14}$. Los borrones se han conservado y nada los diferencia del resto en una narración que no tiene final. Esta virtualidad de la escritura que vuelve constantemente sobre sus propios pasos queda plasmada en el soporte utilizado, el ordenador, y en el intercambio por chat entre Elena/Alsi y Lorenzo. Recordemos que éste le escribe, como en directo, una novela por intérnet. La pantalla del ordenador cumple la función de una pantalla secundaria en la que se puede leer la escritura haciéndose y deshaciéndose pero que también puede reflejar imágenes del mundo real o servir de soporte a imágenes fantasmáticas (cuando Elena/Alsi ve en la

\footnotetext{
14. Si comparamos el guión (MEDEM, 2001) con la película, nos damos cuenta de que ofrece, además de escenas suprimidas como es frecuente, una organización distinta de las secuencias. Esto recalca un hecho banal en sí pero a pesar de todo significativo: que el montaje definitivo no es más que una posibilidad entre un número infinito de otras de las que el guión conserva las huellas.
} 
pantalla de su ordenador el reflejo de Lorenzo acercarse a ella y besarla en el cuello15). En la transmisión instantánea de la escritura cuya lectura apenas es diferida, así como en el destello de la pantalla de ordenador que contamina la del cine mirada por el espectador, surge la dimensión espectral de la escritura como huella, una huella que no existe en el presente sino como un pasado por venir. En esta perspectiva, el intercambio entre Elena/Alsi y Lorenzo podría contemplarse como una clave metonímica de lectura del conjunto de la película.

No pretendo sin embargo reducirla a esta única interpretación totalizadora, es una lectura posible que no excluye las que han sido esbozadas y otras que no aparecen aquí. No he podido estudiar en este marco los innumerables procedimientos de repetición, ecos, recurrencias, sincronicidades que, como siempre en las películas de Medem, señalan la existencia de un orden críptico y subyacente al aparente desorden narrativo. Tampoco he podido resaltar algunas de las implicaciones sicoanalíticas que marcan, por supuesto, la relación ternaria Lorenzo/Luna/Belén y que también apuntan en la dirección de un significado latente. Estos aspectos, muy importantes en Lucía y el sexo, parecen designar la existencia de un sistema coherente que exige una interpretación, un desciframiento (PINTOR, 2008: 123-145). Pero, al mismo tiempo que se va percibiendo un sistema (sea narrativo, simbólico, esotérico, sicoanalítico) se va deconstruyendo y dejando en suspensión las distintas vías interpretativas que coexisten al mismo tiempo que entran en contradicción. Todo esto contribuye a crear una saturación de signos variados e inestables que se van superponiendo como las distintas capas de un milhojas y que indican la existencia de claves que, por su misma proliferación, hacen imposible una interpretación unicista que pueda abarcar las múltiples facetas de una película en constante proceso de diseminación y de «diferancia» de su sentido.

El carácter diseminado de la narración hace posible varios relatos que se van contradiciendo unos a otros lo cual induce una indecidibilidad entre las dos grandes vertientes posibles de la película. No se trata de optar por una u otra

15. Escena 14 de la edición DVD. 
y decidir si los personajes viven una tragedia en su nivel de realidad o si sólo la proyecta Lorenzo en sus escritos, si el narrador secundario y la enunciación primera son una misma instancia, se trata de admitir que no se puede zanjar, que las dos eventualidades existen juntas, no porque la película sea polisémica -y respecto a esta noción, siempre insistió Derrida en que la diseminación no era lo mismo que la polisemia (DERRIDA, 1972a) - sino porque cada opción brota de la otra y a su vez la genera. Lo que Lucía y el sexo pone de manifiesto es que no sólo el sentido es múltiple sino que va construyéndose al mismo tiempo que se deconstruye y que estos procesos no son en absoluto sucesivos sino simultáneos e inherentes. Dejaré que concluya Derrida a propósito de este proceso de constante germinación: «[1]a inseminación "primera" es diseminación. Huella, injerto del que se pierde la huella. Que se trate de lo que llamamos "lenguaje" (discurso, texto, etc.) o de sembradura "real", cada término es un germen, cada germen es un término. El término, el elemento atómico, engendra dividiéndose, injertándose, proliferando. Es una semilla y no un término absoluto. Pero cada germen es su propio término, posee su término no fuera de sí sino en sí como su propio límite interior, haciendo ángulo con su propia muerte» ${ }^{6}$.

\section{Referencias Bibliográficas}

DERRIDA, Jacques (1972): Marges - de la philosophie, Paris, Éditions de Minuit. DERRIDA, Jacques (1972a): «La double séance» en La dissémination, Paris, Editions du Seuil.

DERRIDA, Jacques (2002): Au-delà des apparences, (entrevista con Antoine Spire) Bordeaux, Le Bord de l'Eau.

GARCÍA DÜTTMANN, Alexander (2004): "Poésie et vérité de la déconstruction", en Europe, Jacques Derrida, n 901 , mayo.

GENETTE, Gérard (1972): Figures III, Paris, Editions du Seuil.

\footnotetext{
16. «L'insémination "première" est dissémination. Trace, greffe dont on perd la trace. Qu'il s'agisse de ce qu'on appelle "langage" (discours, texte, etc.) ou d'ensemencement "réel", chaque terme est bien un germe, chaque germe est bien un terme. Le terme, l'élément atomique, engendre en se divisant, en se greffant, en proliférant. C'est une semence et non un terme absolu. Mais chaque germe est son propre terme, a son terme non pas hors de soi mais en soi comme limite intérieure, faisant angle avec sa propre mort» (DERRIDA, 1972a: 337-338).
} 
GROSSMAN, Evelyne (2004): "La vérité blessante" en Europe, Jacques Derrida, $\mathrm{n}^{\circ}$ 901, mayo, pp. 18-22.

HABERMAS, Jürgen (1988): Le discours philosophique de la modernité, Paris, Gallimard.

MEDEM, Julio (2001): Lucía y el sexo, Madrid, Ocho y Medio Libros de Cine.

METZ, Christian (1991): L'énonciation impersonnelle ou le site du film, Paris, Méridiens Klincksieck.

PINTOR, Iván (2008): «Los rostros de Mari: el cine de Julio Medem y el imaginario mitológico vasco» en Le cinéma de Julio Medem (Marie-Soledad Rodríguez ed.), Paris, Presses de la Sorbonne Nouvelle, pp. 123-145

THIBAUDEAU, Pascale (2005): «La función del círculo en la elaboración espacio-temporal de las películas de Julio Medem», en Historia (s), Motivos y formas del cine español (Pedro Poyato Sánchez dir.), Córdoba, Editorial Plurabelle.

ZYMA, Pierre V. (1994): La déconstruction. Une critique, Paris, P.U.F. 